Finisterra, XXXIII, 66, 1998, pp. 77-89

\title{
VARIABILIDADE DA PRECIPITAÇÃO EM PORTUGAL E RELAÇÕES COM O SISTEMA OCEANO-ATMOSFERA NO ATLÂNTICO NORTE
}

PEDRO TILDES GOMES ${ }^{1}$

Resumo - A variabilidade da precipitação em Portugal, no período 1900-1993, é estudada a partir de um índice pluviométrico mensal e estacional que foi construído utilizando uma Análise em Componentes Principais (ACP). Esse índice é constituído pela série temporal do primeiro factor que ultrapassa sempre os $60 \%$ de explicação da variância total. Procuram-se relações entre a variabilidade pluviométrica em Portugal Continental e o comportamento do sistema oceano-atmosfera no Atlântico Norte. Para o efeito escolheram-se dois parâmetros para serem confrontados com o índice pluviométrico: a temperatura de superfície do oceano (TSO) e o campo do geopotencial a $850 \mathrm{hPa}$ na atmosfera do Atlântico Norte. A análise dos ciclos revelou uma variabilidade da precipitação que poderá estar ligada com a TSO. Ciclos significativos de 3, 4 e $7 / 8$ anos foram detectados quer na TSO, quer no índice pluviométrico. Foi elaborado um mapa de correlação entre o índice pluviométrico e o campo da TSO e, também, uma análise compósita da TSO para testar a diferença entre os anos mais chuvosos e os mais secos. Os padrões resultantes nos dois casos denotam uma estreita relação entre a variabilidade da TSO e a da precipitação, mas também a existência de uma repartição diferente da TSO para os anos chuvosos e para os anos secos. Da correlação entre o índice pluviométrico e o campo do geopotencial a $850 \mathrm{hPa}$ ressalta o modo da Oscilação do Atlântico Norte (NAO). As correlações entre o índice pluviométrico e os índices da NAO à escala mensal, revelam que é entre Dezembro e Março que a influência da NAO é mais marcada e significativa.

Palavras-Chave: Variabilidade da precipitação, índice pluviométrico, sistema Oceano-Atmosfera, estação chuvosa.

\begin{abstract}
Rainfall Variabiltty In Portugal And Some Relations With The Ocean-ATMOSPHERE SYSTEM IN THE NORTH ATLANTIC - The scope of this study is to analyse rainfall variability in the Portuguese rainy season (Nov-Mar) during the 20th century, and examine some relations with the sea surface temperatures (SST) and geopotential heights at $850 \mathrm{hPa}(\mathrm{Z} 850)$ in the North Atlantic region. To build the Portuguese rainfall index (PRI), a principal component analysis (PCA) was performed on a matrix containing seven Portuguese stations with secular records (variables) and the years 1900 to 1993 (observations). This index is the first principal
\end{abstract}

${ }^{1}$ Investigador do Centro de Estudos Geográficos da Universidade de Lisboa. (Endereço do CEG no início do volume). E-mail: t00049@mail.telepac.pt 
component $(\mathrm{PC})$, which explains always over $60 \%$ of the total variance and all the seven stations used in the PCA have positive correlations with the first component. Therefore we can assume that the first PC describes the rainfall variability in Portugal and the PCA has detected only one coherent area in Portuguese territory. The analysis of cycles reveals a variability that might be linked with the North Atlantic ocean-atmosphere system. Very significant cycles of $3 / 4$ or $7 / 8$ years were found either in the PRI or in the first PC of SST time-series. In order to search the causes of the rainfall variability in Portugal, several correlations and composites analysis were made. Correlations between the PRI and the North-Atlantic Oscillation (NAO) index are always negative for all rainy season months (Nov-Mar). The correlation between the PRI and the SST in North Atlantic shows a central area with significant negative coefficients (west of Portuguese coastline). Positive correlations above $50^{\circ} \mathrm{N}$ and below $30^{\circ} \mathrm{N}$. The correlation between the PRI and Z850 field shows a North-Atlantic Oscillation (NAO) pattern: positive correlations in the North and negative correlations in the south of North Atlantic Region. In addition, a composite analysis was made for wet and dry years to test the reaction of the SST field. A distinct pattern was found in the SST field for wet an dry years.

Key words: Rainfall variability, Portuguese rainfall index, ocean-atmosphere system, rainy season

\section{I - INTRODUÇÃO}

O objectivo deste estudo é a análise de algumas conexões entre a variabilidade da precipitação, de Novembro a Março, a temperatura da superfície do oceano (TSO) e o campo de geopotencial da atmosfera ao nível dos $850 \mathrm{hPa}$ (Z850), em todo o Atlântico Norte. Trata-se de procurar alguns elementos explicativos da varibilidade da precipitação em Portugal Continental. Esta variabilidade tem sido estudada numa perspectiva mais espacial, do que temporal. A variabilidade espacial da precipitação em Portugal Continental mereceu uma atenção especial dos geógrafos (DAVEAU e Col., 1977; VENTURA, 1994; FRAGOSO, 1994), ao contrário da variabilidade temporal (ALCOFORADO, 1984; GOMES, 1994). Os estudos em que se procura determinar as causas da variabilidade da precipitação em Portugal são ainda mais raros entre os geógrafos FERREIRA, 1989; MAHERAS et al., 1994). Esta via de investigação foi sobretudo praticada pelos geofísicos (CORTE-REAL,1995a,1995b, 1998).

\section{II - OS DADOS E A METODOLOGIA}

Os dados de precipitação foram obtidos a partir do ficheiro Global Historical Climatology Network (VOSE et al, 1992). Este ficheiro tem a vantagem de a homogeneidade das séries ter sido testada pelos autores. As técnicas utilizadas para a detecção de eventuais problemas de homogeneidade, bem como a forma de os corrigir, vem referida em T. C. Peterson e D. R. EASterling (1994) e D. R. EAsterling e T. C. Peterson (1995). No entanto, o referido ficheiro tem falhas de dados em algumas estações meteorológicas. Nestes casos, recorreu-se às publicações do Instituto de Meteorologia (I.M.). Nas estações onde foi necessário completar as séries de dados, a homogeneidade das mesmas teve que ser de novo verificada, com base em testes e métodos referidos em PETERSON e EASTERLING (1994), assim como em EASTERLing e PETERSON (1995). 


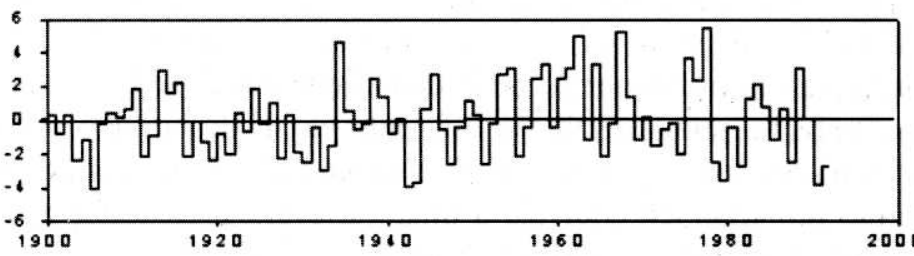

NOV. / MARÇO

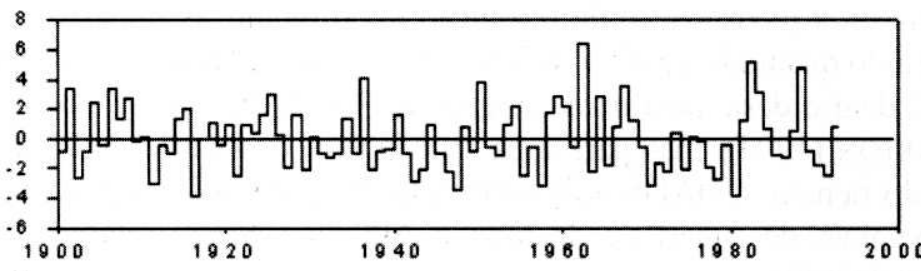

NOVEMBRO

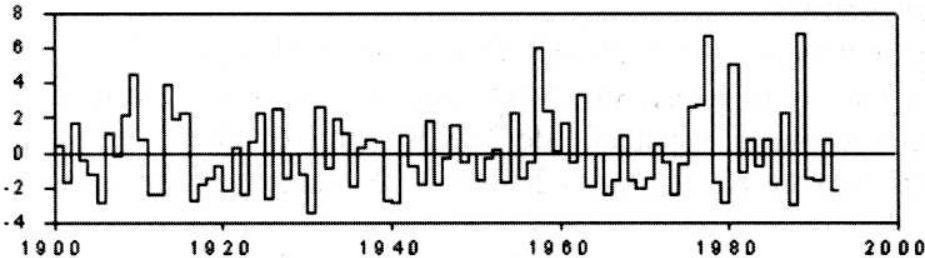

DEZEMBRO

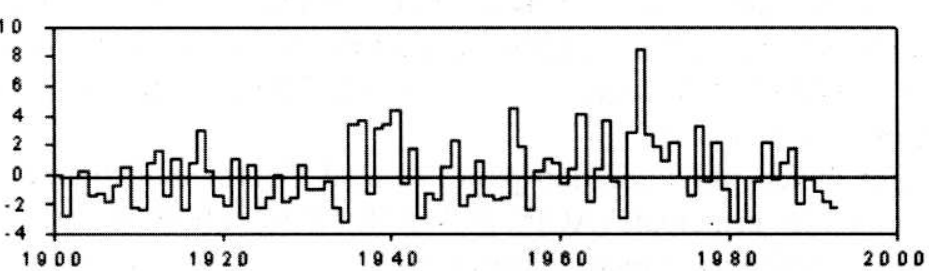

JANEIRO

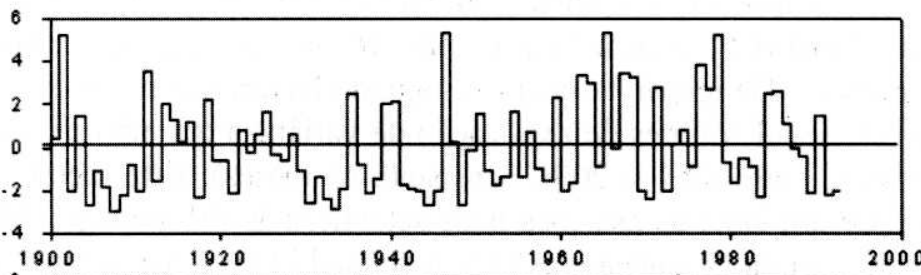

FEVEREIRO

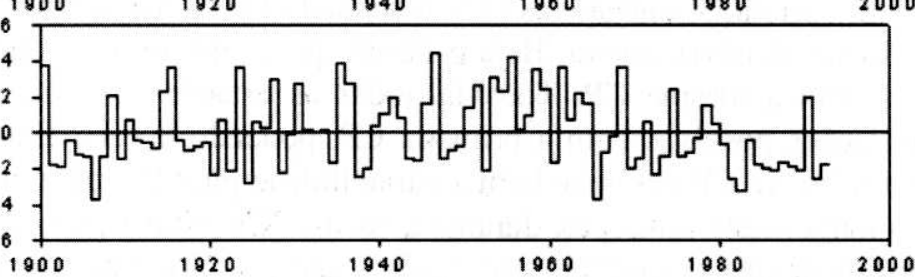

\section{MARÇO}

Fig. 1 - Índice pluviométrico para Portugal Continental às escalas estacional e mensal.

Fig. 1 - Pluviometric Index for Portugal. 
Os dados da temperatura da superfície do oceano (TSO) para o Atlântico Norte foram retirados do ficheiro Comprehensive Ocean-Atmosphere Data Set (COADS). Estes dados estão disponíveis numa resolução de $2^{\circ}$ de latitude por $2^{\circ}$ de longitude, mas foram utilizados neste trabalho numa resolução diferente: de $4^{\circ}$ de latitude por $4^{\circ}$ de longitude. Esta transformação justifica-se não só pela diminuição do número de variáveis a tratar (cada ponto no Atlântico equivale a uma variável), mas também porque uma diminuição na resolução conduz a uma diminuição do "ruído" e da informação redundante. Além disso, a modificação da resolução faz diminuir as falhas de dados, uma vez que a média do quadrado de $4^{\circ} \times 4^{\circ}$ foi determinada por um qualquer registo da quadrícula de $2^{\circ} \times 2^{\circ}$, dentro desta área mais alargada de $4^{\circ} \times 4^{\circ}$. Esta metodologia foi já utilizada por BARNSTON (1994), mas para uma mudança de resolução de $2^{\circ} \times 2^{\circ}$ para $10^{\circ} \times 10^{\circ}$. Os dados do ficheiro COADS utilizados neste trabalho estão organizados em anomalias de temperatura de superfície de todo o Atlântico Norte, relativamente à média do período de $1950-93$.

Os dados de geopotencial a $850 \mathrm{hPa}$ (Z850) foram retirados do ficheiro de OORT (iniciado em 1983), para todo o período disponível, ou seja, entre Abril de 1958 e Dezembro de 1989. A resolução espacial é de $2^{\circ}$ e $30^{\prime}$ em latitude e $5^{\circ}$ em longitude, cobrindo a região atlântica entre as latitudes $20^{\circ} \mathrm{N} \mathrm{e} 90^{\circ} \mathrm{N}$ e entre as longitudes $90^{\circ} \mathrm{W}$ e $50^{\circ} \mathrm{E}$.

Sete estações meteorológicas portuguesas foram escolhidas ao longo de um transepto Norte-Sul, entre Montalegre e Faro durante um período de funcionamento comum, ou seja, entre 1900 e 1993 (Montalegre; Porto/Serra do Pilar; Coimbra/Geofísico; Lisboa/Geofísico; Évora; Beja; Faro).

Para construir um índice pluviométrico para Portugal Continental, optou-se por uma análise em componentes principais (ACP). A ACP foi efectuada sobre uma matriz contendo como variáveis (colunas) a precipitação mensal (ou estacional) nas sete estações meteorológicas e, em observações (linhas), os anos (1900-1993). O índice é a primeira componente principal (CP), a qual tem sempre uma percentagem de explicação da variância superior a $60 \%$. De referir, também, o segundo factor, que regista em todos os meses e à escala estacional, valores de explicação de variância que não são de desprezar (aproximadamente entre $13 \%$ e $20 \%$, consoante os meses). Este factor retrata uma oposição entre, por um lado, as estações mais setentrionais (Montalegre, Porto e Coimbra) que registam correlações negativas com a segunda $\mathrm{CP}$ e, por outro lado, as estações mais meridionais (Lisboa, Évora, Beja e Faro), que registam, por seu turno, correlações positivas com a mesma CP. Todavia, todas as estações meteorológicas (variáveis) têm correlações positivas com a primeira $\mathrm{CP}$, podendo-se, então, assumir com segurança que a primeira $\mathrm{CP}$ descreve bem a variabilidade pluviométrica em Portugal Continental ao longo deste transepto, durante o século XX. Numa primeira análise, poderemos considerar que o território português reage em bloco no que toca à variabilidade da precipitação à escala mensal (e estacional). Assim, pode-se desde já concluir que, ao longo do transepto estudado, a precipitação não regista contrastes significativos de variabilidade. Em outras palavras, se chover acima do normal no Porto é provável que, pelo menos à escala mensal, chova também acima do normal em Faro. 
As conexões entre a variabilidade pluviométrica em Portugal e o sistema Oceano-Atmosfera no Atlântico Norte foram investigadas a partir das correlações entre um índice da Oscilação do Atlântico Norte (neste caso o índice construído por HURREL, 1995) e o índice pluviométrico português. Foi também realizada uma análise compósita, com a finalidade de estudar a característica do campo da TSO nos anos classificados como secos e chuvosos.

\section{III - O ÍNDICE PLUVIOMÉTRICO PARA PORTUGAL CONTINENTAL ÀS ESCALAS ESTACIONAIS E MENSAIS}

Pela análise da figura 1, facilmente se pode verificar a ausência de uma tendência à escala secular. Contudo, há alguns aspectos de pormenor que interessa analisar. Nas décadas de 80 e 90, em particular nos meses de Janeiro, Fevereiro e Março, predominam as anomalias negativas, anomalias estas que, ocorrendo em anos consecutivos, formam sequências de anos secos. Estão neste caso as duas sequências bem representadas na figura (nos meses em questão) que correspondem aos períodos de seca que ocorreram em Portugal no início das décadas de 80 e 90 . Estes períodos secos são também visíveis à escala estacional (Novembro a Março).

No geral, também nas décadas de 30 e 40 houve registo de um maior número de anomalias negativas.

As épocas mais chuvosas do século XX ocorreram, sobretudo, nas décadas de 60 e 70 para os meses de Janeiro e Fevereiro. Para os meses de Novembro e Dezembro há um contraste entre a década de 60 (predomínio das anomalias positivas) e a década de 70 (predomínio das anomalias negativas).

O mês de Março tem um comportamento particular no que toca à variabilidade da precipitação. Assim, é visível uma tendência de sinal negativo que tem início na década de 60, que se traduz numa diminuição, mais ou menos gradual, dos quantitativos de precipitação. Este facto está já bem documentado na literatura científica e fala-se, inclusivamente, num estreitamento da estação chuvosa, em virtude de um mês de Março de características cada vez mais associadas à secura. CORTE-REAL et al. (1998) referem que a tendência negativa da precipitação em Março, está intimamente relacionada com as tendências igualmente negativas nas frequências de um regime de circulação associado a um modo chuvoso, identificado pelos autores. A reforçar esta ideia, há um concomitante aumento de frequência do modo de circulação de tipo estival, associado à secura.

\section{IV - AS RELAÇÕES ENTRE A VARIABILIDADE DA PRECIPITAÇÃO E O COMPOR- TAMENTO DO SISTEMA OCEANO-ATMOSFERA DO ATLÂNTICO NORTE}

\section{1 - As Temperaturas de Superfície do Oceano (TSO)}

No sentido de fazer um primeiro teste à relação entre a variabilidade pluviométrica e o campo das TSO no Atlântico Norte, durante a estação chuvosa (Novembro a 
Março), foi efectuada uma análise espectral à primeira $\mathrm{CP}$ da precipitação e à primeira CP da TSO. A análise dos ciclos permitiu levantar a hipótese de uma estreita ligação entre a variabilidade pluviométrica e a variabilidade da TSO no Atlântico Norte. Ciclos significativos (com um intervalo de confiança de 95\%) de 3, 4, 7/8 anos foram registados, quer no índice pluviométrico à escala estacional, quer na série temporal da primeira CP da TSO.

A correlação do índice pluviométrico estacional com o campo da TSO no Atlântico Norte (fig.2), resulta num padrão de correlação negativa numa região que se estende em sentido NE-SW, em oposição a duas regiões, uma mais setentrional, outra mais meridional de correlação positiva.

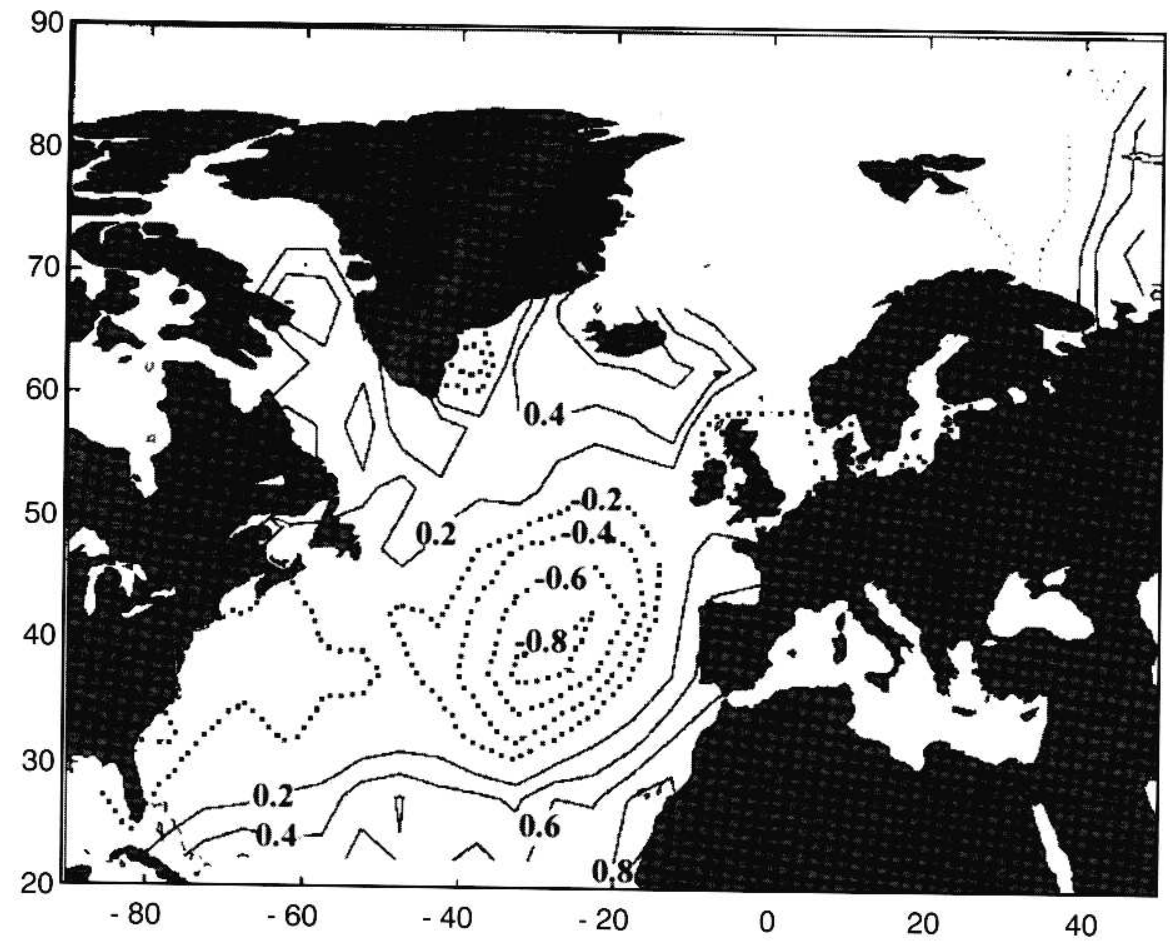

Fig. 2 - Correlação entre o índice pluviométrico e o campo da temperatura de superfície do oceano (1950-1993), à escala estacional (Novembro-Março).

Fig. 2 - Correlation between the pluviometric index and sea surface temperature from November to March.

O núcleo da correlação negativa mais elevada está centrado a oeste do litoral de Portugal, na região dos Açores e a Noroeste da Madeira. Por seu lado, a correlação positiva mais elevada ocorre, quer em torno da Islândia, quer numa região mais meridional, afectada pela corrente fria das Canárias e mais para ocidente ao longo da latitude de $20^{\circ} \mathrm{N}$. 
$\mathrm{Na}$ área de correlação positiva, a variabilidade da TSO está em fase com a variabilidade da precipitação em Portugal Continental, ou seja, a anomalias positivas na TSO será de esperar, em média, anomalias positivas na precipitação. O mesmo será dizer que, a anomalias positivas na TSO, correspondem anos com precipitação acima do normal, podendo o mesmo raciocínio ser feito de forma equivalente para os anos de precipitação abaixo do normal. Este resultado fornece uma primeira hipótese de trabalho: quando se verifica um enfraquecimento da corrente fria das Canárias, espelhado num aumento da temperatura de superfície das águas oceânicas, será de esperar que ocorra um período de precipitação acima do normal em Portugal Continental. $\mathrm{Na}$ área de correlação negativa a variabilidade da TSO está, então, em oposição de fase com a variabilidade da precipitação. Assim, a anomalias positivas da TSO, correspondem anos secos, enquanto a valores de TSO abaixo da média estão associados anos chuvosos.

Quadro I - Meses secos e chuvosos que entraram

para o cálculo das médias da análise compósita.

Table I - Dry and wet months used for the composite analysis.

\begin{tabular}{|l|l|l|}
\hline & \multicolumn{1}{|c|}{ Anos mais Chuvosos } & \multicolumn{1}{c|}{ Anos mais secos } \\
\hline Novembro & $\begin{array}{l}1955,1959,1962,1963,1965,1968, \\
1976,1978,1989\end{array}$ & $\begin{array}{l}1952,1956,1966,1979,1980,1982, \\
1988,1991,1992\end{array}$ \\
\hline Dezembro & $\begin{array}{l}1958,1963,1976,1977,1978,1981, \\
1989\end{array}$ & $\begin{array}{l}1964,1966,1970,1974,1980,1988, \\
1993\end{array}$ \\
\hline Janeiro & $1955,1963,1966,1970,1977$ & $1957,1968,1981,1983,1993$ \\
\hline Fevereiro & $1963,1966,1968,1969,1977,1993$ & $1971,1973,1984,1990,1992,1993$ \\
\hline Março & $1952,1954,1956,1959,1962,1969$ & $1953,1966,1973,1982,1983,1992$ \\
\hline
\end{tabular}

Os anos foram escolhidos tendo em atenção o valor do índice pluviométrico para Portugal Continental. Os anos mais chuvosos e os mais secos são os que apresentam, respectivamente, anomalias positivas e negativas de maior valor absoluto.

A análise compósita que seguidamente se apresenta, destina-se a testar a ligação entre a variabilidade da TSO e a variabilidade da precipitação em Portugal Continental. Para o efeito, é necessário constituir duas amostras (para cada mês em análise Novembro a Março), correspondendo uma delas aos anos de anomalias positivas mais elevadas, e uma outra constituída pelos anos de anomalias negativas de maior valor absoluto. Esta escolha tem como base o índice pluviométrico para Portugal Continental, representado na figura 1. De seguida, calculam-se duas médias para a TSO, respeitando a divisão por grupo de anos feita anteriormente. A diferença entre estas médias é testada pelo teste " $t$ " de Student, no sentido de verificar se é significativa. Os vários grupos de anos correspondendo aos anos mais chuvosos e mais secos (respectivamente de anomalias mais positivas e de anomalias mais negativas) foram reunidos no Quadro I, mas só foram considerados os anos posteriores a 1950, uma vez que os dados de TSO são mais fiáveis a partir desta data. 
Após o cálculo das diferenças entre as médias da TSO (média dos anos chuvosos-média dos anos secos), seguiu-se a respectiva representação cartográfica. A diferença positiva delimita áreas onde as médias de TSO dos anos húmidos são superiores às dos anos secos. Pelo contrário, a diferença negativa delimita áreas em que a média das anomalias da TSO é mais elevada nos anos secos (fig.3).

Para simplificar a análise, na figura 3 só foram representadas as áreas nas quais as diferenças entre as médias (positivas ou negativas) são significativas de acordo com o teste " $t$ " de Student.

Em Novembro é visível um núcleo de diferença negativa a ocidente da Península Ibérica, que se mantém nos dois meses seguintes, em Dezembro e Janeiro, com ligeiras diferenças de posição. Este núcleo retrata uma região do Atlântico em que a média da TSO nos anos secos é superior à dos anos chuvosos. Ainda, no mês de Novembro, a diferença positiva significativa reparte-se por três áreas: uma ao longo da costa ocidental africana, uma outra a sudoeste das Canárias e, finalmente uma terceira, a mais extensa, centrada entre $60^{\circ} \mathrm{W}$ e $40^{\circ} \mathrm{W}$ e entre $30^{\circ} \mathrm{N}$ e $50^{\circ} \mathrm{N}$.

Em Dezembro mantém-se, no essencial, o padrão verificado em Novembro. No entanto, há um novo núcleo de diferenças negativas junto à Terra Nova. As diferenças positivas estão agora situadas na região percorrida pela corrente fria das Canárias. Esta disposição mantém-se, sem grandes alterações, nos dois meses seguintes, Janeiro e Fevereiro.

Em Janeiro, e sobretudo em Fevereiro, marca-se melhor o contraste entre a região da corrente fria das Canárias (diferença positiva) e a região atravessada pela corrente quente do Golfo e pela sua deriva para Norte (diferença negativa).

Ao contrário dos outros meses, em Março não se registam praticamente diferenças significativas entre as médias dos anos chuvosos e dos anos secos. Por este facto, o referido mês não se encontra representado na figura 3, pois não há factos relevantes para a análise que justifiquem a sua inclusão.

Duas principais conclusões ressaltam desta análise. Em primeiro lugar, existem padrões típicos de TSO para anos chuvosos e para anos secos. Em segundo lugar, as anomalias da TSO quer na corrente quente do Golfo, quer na corrente fria das Canárias parecem estar ligadas com a variabilidade da precipitação em Portugal Continental. Assim, anomalias positivas nas TSO, traduzindo um enfraquecimento na corrente fria das Canárias, parecem estar relacionadas com anos chuvosos. O raciocínio inverso também é válido, uma vez que a um fortalecimento da corrente fria das Canárias, consequência de anomalias negativas na TSO da região, estão associados anos secos. As anomalias positivas nas TSO na área percorrida pela corrente quente do Golfo, parecem estar, também, relacionadas com anos secos em Portugal Continental, enquanto anomalias de sinal contrário, que conduzem a um enfraquecimento da corrente do Golfo, estão associados aos anos chuvosos. A hipótese lançada anteriormente, sobre a ligação entre as duas principais correntes do Atlântico Norte e a variabilidade da precipitação em Portugal Continental, parece ganhar forma. Será de todo o interesse, então, poder vir a comprovar ou reforçar a hipótese, em trabalhos futuros, de que o padrão da TSO nos 

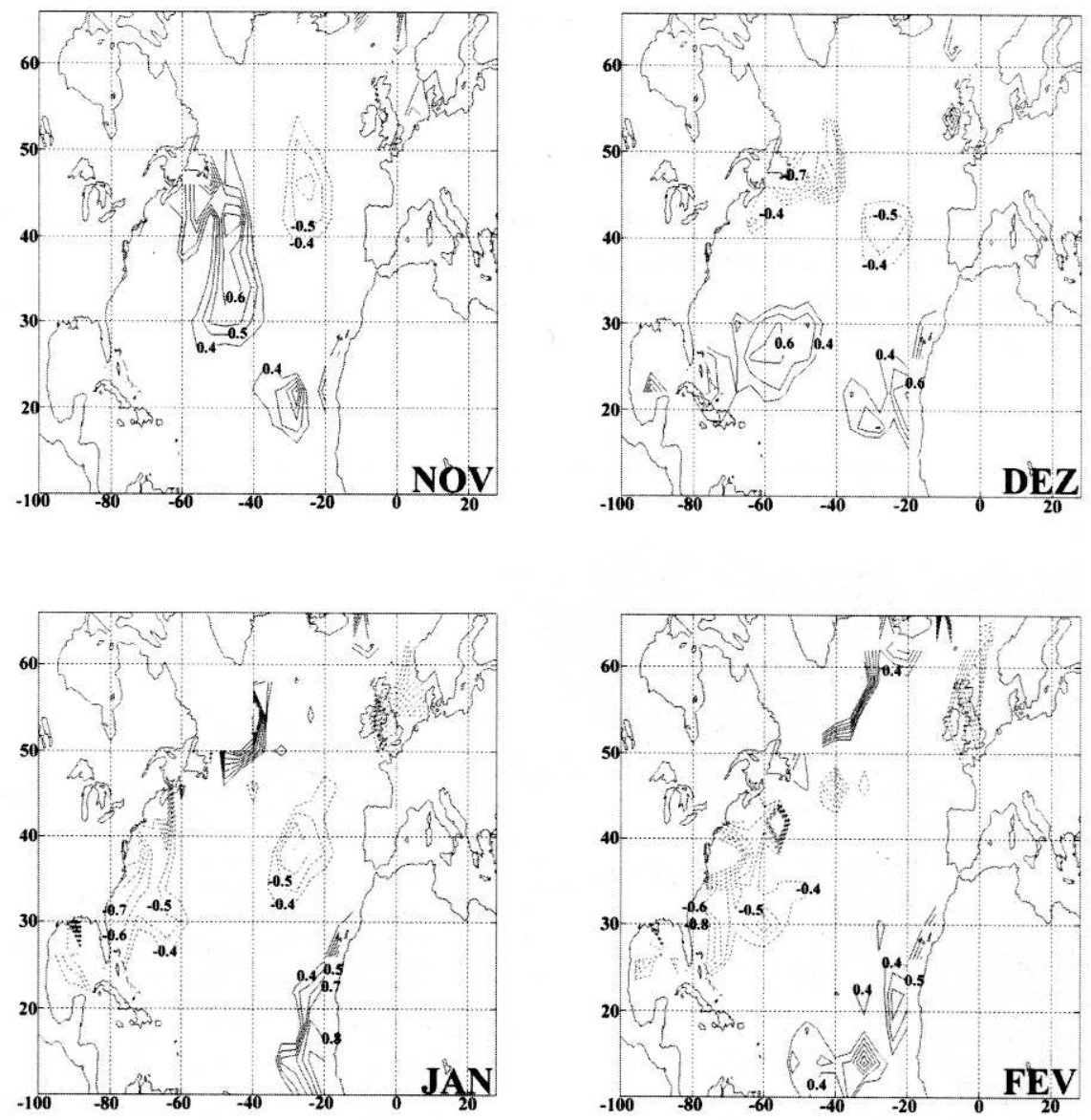

Fig. 3 - Análise compósita da temperatura de superfície do Oceano Atlântico Norte. (Só estão representadas as áreas onde as diferenças de TSO entre as médias dos anos mais chuvosos e dos anos mais secos são significativas de acordo com o teste " $t$ " de Student).

Fig. 3 - Composite analysis of sea surface temperature (TSO) of the North Atlantic Ocean. 
anos chuvosos consistirá num enfraquecimento das duas principais correntes do Atlântico Norte: anomalias positivas da TSO na corrente fria das Canárias e anomalias negativas da TSO na corrente quente do Golfo. Da mesma forma, será interessante verificar se o padrão dos anos secos se materializa por um fortalecimento das duas correntes já mencionadas, devido a anomalias negativas na corrente fria das Canárias (reforçando o seu carácter frio) e anomalias positivas na corrente quente do Golfo (reforçando o seu carácter quente), tornando, desta forma, mais marcado o gradiente NW-SE da TSO entre estas duas correntes.

\section{2 - Relações com a Atmosfera do Atlântico Norte}

A correlação entre o índice pluviométrico e o campo do geopotencial a $850 \mathrm{hPa}$ (Z850) à escala estacional, entre Novembro e Março (fig. 4), resulta num padrão típico, definido como uma estrutura dipolar, de orientação Norte-Sul, conhecida por Oscilação do Atlântico Norte (NAO).

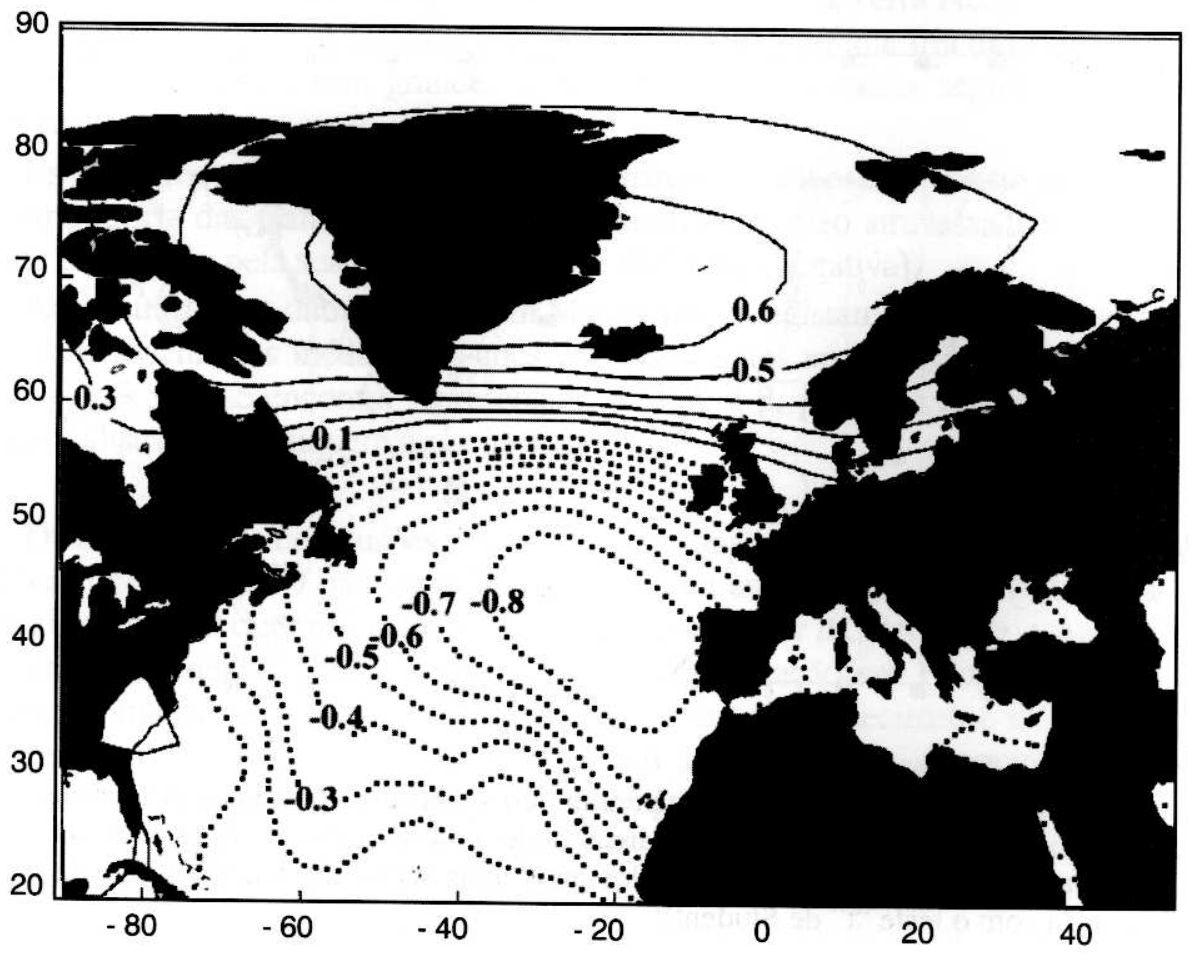

Fig. 4 - Correlação entre o índice pluviométrico e o geopotencial a $850 \mathrm{hPa}$ (1959-1989), à escala estacional (Novembro-Março).

Fig. 4 - Correlation between the pluviometric index and the $850 \mathrm{hPa}$ geopotential. 
A correlação é negativa em todo o Atlântico Norte, a sul de $55^{\circ} \mathrm{N}$, enquanto a correlação positiva se regista nas latitudes mais elevadas. A correlação positiva mais elevada está centrada na Islândia e em parte da Gronelândia, enquanto a correlação negativa mais elevada se centra no Atlântico Oriental, imediatamente a Oeste da Península Ibérica.

A variação da precipitação, em Portugal, está em fase com a variação do campo de pressão a $850 \mathrm{hPa}$ registada nas latitudes mais elevadas, região normalmente ocupada pela depressão da Islândia. Ao contrário, a variação da precipitação está em oposição de fase na região mais meridional do Atlântico Norte.

A variação meridiana dos coeficientes de correlação, denota uma compressão do gradiente na passagem dos valores negativos para os positivos. Esse aumento do gradiente na variação dos coeficientes de correlação, espelha a interacção entre os dois organismos dinâmicos de pressão que dominam o Atlântico Norte: a depressão da Islândia e as altas pressões tropicais, materializadas à superfície pelo anticiclone subtropical dos Açores.

Para completar a informação da figura 4, foram calculadas correlações entre o índice pluviométrico e um índice da NAO (HuRREL, 1995). O coeficiente de correlação é baixo na escala estacional e, de igual forma, nos meses de Novembro e Abril. Nestes meses particulares, os principais mecanismos explicativos da variabilidade da precipitação não se encontram na Oscilação do Atlântico Norte. Uma hipótese a investigar será a maior mobilidade dos organismos de pressão no Atlântico Norte, durante estes dois meses, na transição para os regimes estival e invernal. Durante este processo, o gradiente de pressão entre as altas e as baixas pressões torna-se mais diluído e o seu sinal, de acordo com o coeficiente de correlação, torna-se menos nítido. Entre Dezembro e Março, o coeficiente de correlação ultrapassa o valor de -0.5 , deixando clara a influência da NAO (Quadro II).

Quadro II - Coeficientes de correlação entre um índice da NAO e o índice pluviométrico para Portugal Continental

Table II - Correlation between the NAO Index and the pluviometric index for Portugal

\begin{tabular}{|lc|}
\hline Meses & $\begin{array}{c}\text { Coeficiente de } \\
\text { correlação }\end{array}$ \\
\hline Novembro & -0.32 \\
\hline Dezembro & -0.53 \\
\hline Janeiro & -0.56 \\
\hline Fevereiro & -0.59 \\
\hline Março & -0.58 \\
\hline Abril & -0.27 \\
\hline
\end{tabular}




\section{V - CONCLUSÃO}

Nesta primeira análise das relações entre a variabilidade da precipitação em Portugal Continental e o comportamento do sistema oceano-atmosfera do Atlântico Norte, emergem diversas hipóteses de trabalho que merecem ser investigadas de forma mais aprofundada. Neste estudo só as temperaturas de superfície do oceano e o campo do geopotencial a $850 \mathrm{hPa}$ foram analisados. Será necessário, posteriormente, ter em conta um maior número de parâmetros descritores do estado do sistema oceano-atmosfera. Da mesma forma, dever-se-ão confirmar as características da variabilidade pluviométrica em Portugal Continental, alargando a rede das estações meteorológicas.

Este estudo conduz a duas vias de investigação:

- O papel da corrente quente do Golfo e da corrente fria das Canárias, parece ser importante na explicação da variabilidade pluviométrica, principalmente entre Novembro e Fevereiro.

- A Oscilação do Atlântico Norte, o principal modo de variabilidade do campo de pressão nesta região, parece controlar a variabilidade pluviométrica entre Dezembro e Março, enquanto a sua influência é bastante atenuada em Novembro e Abril.

\section{BIBLIOGRAFIA}

ALCOFORADO, M.J. (1984) - Quelques Remarques sur l'Évolution Séculaire des Précipitations à Lisbonne. Três Estudos de Geografia Física, Linha de Acção de Geografia Física, Relatório n $^{\circ} 21, \mathrm{CEG}$, INIC: $12-27$.

BARNSTON, A.G. (1994) - Linear Statistical Short-Term Climate Predictive Skill in the Northern Hemisphere. Journal of Climate, 7: 1513-1564

DAVEAU, S. e COL. (1977) - Répartition et Rythme des Précipitations au Portugal. Memórias do Centro de Estudos Geográficos, n³, Lisboa, 192p.

CORTE-ReAl, J.; ZHANG, X.; WANG, X. (1995a) - Downscaling GCM Information to regional Scales: A Non-parametric Multivariate Regression Approach. Climate Dynamics, 11: 413-424.

CORTE-REAL, J.; ZHANG, X.; WANG, X. (1995b) - Large-Scale Circulation regimes and Surface Climatic Anomalies over the mediterranean. International Journal of Climatology, 15: 1135-1150.

Corte-Real, J.; Budong QIAN; Hong Xu (1998) - Regional Climate Change in Portugal: Precipitation Variability Associated With Large-Scale Atmospheric Circulation. International Journal of Climatology, 18: 619-635.

EASTERLING, D.R.; PETERSON, T.C. (1995) - A New Method for Detecting Undocumented Discontinuities in Climatological Time Series. International Journal of Climatology, 15: 369-377.

FERREIRA, D.B. (1989) -Le climat de l'Atlantique Orientale des Açores aux îles du Cap Vert. Contribution à l'étude du systéme ocean-atmosphére. Thèse de Doctorat d'État, Universidade de Paris-Sorbonne, 1657p. (difusão microfichada)

FRAGOSO, M. (1994) - Aspectos da variabilidade espacial das precipitações na Estremadura. Dissertação apresentada à Faculdade de Letras da Universidade de Lisboa para a obtenção do Grau de Mestre em Geografia Física e Regional, 187p. (não publicado) 
GOMES, P. T. (1994) - A variabilidade climática em Portugal Continental durante o século XX. Estudo estatístico da temperatura e da quantidade de precipitação. Dissertação de mestrado em Geografia Física e Regional, Universidade de Lisboa, 207p. + Atlas. (não publicado)

HurRel, J. W. (1995) - Decadal Trends in the North Atlantic Oscillation: Regional Temperatures and Precipitation. Science, 269: 676-679.

Peterson, T.C.; ESATERLING, D.R. (1994) - Creation of Homogeneous Composite Climatological Reference Series. International Journal of Climatology, 14: 671-679.

MAHeras, P.; AlCOFORADO, M. J.; GuIKA, S.; VAFIADIS, M. (1994) - Relations entre les périodes sèches et humides des précipitations et les indices de circulation atmosphérique au Portugal durant la dernière période séculaire. Publications de l'Association Internationale de Climatologie, 7: 241-248.

OORT A.H. (1983) - Global Atmospheric Circulation Statistics:1958-73. NOAA Professional Paper, $\mathrm{n}^{\circ} 14$, Rockville, 179p.

VENTURA, J. (1994) - As precipitações no Sul de Portugal (ritmo e distribuição espacial). Tese de Doutoramento em Geografia e Planeamento Regional, Universidade Nova de Lisboa, 381p. (não publicado)

Vose, R. S., Richard L. Schmoyer, Peter M. Steurer, Thomas C. Peterson, Richard HeIM, THOMAS R. KARL, AND J. EISCHEID (1992) - The Global Historical Climatology Network: long-term monthly temperature, precipitation, sea level pressure, and station pressure data. ORNL/CDIAC-53, NDP-041. Carbon Dioxide Information Analysis Center, Oak Ridge National Laboratory, Oak Ridge, Tennessee. 